\title{
Spontaneous Knotting of a Foley Catheter in the Urinary Bladder: A Case Report
}

\section{Menbeu Sulta*}

Department of Emergency Medicine and Critical Care, St. Paul Hospital Millennium Medical College, Addis Ababa, Ethiopia

*Corresponding author: Menbeu Sulta, Assistant Professor of Emergency Medicine, St. Paul Hospital Millennium Medical College, Department of Emergency Medicine and Critical Care, Addis Ababa, Ethiopia, Tel: 251911917 733; E-mail: smenbeu@yahoo.com

Received date: September 30, 2017; Accepted date: October 30, 2017; Published date: November 07, 2017

Copyright: (c) 2017 Sulta M. This is an open-access article distributed under the terms of the Creative Commons Attribution License, which permits unrestricted use, distribution, and reproduction in any medium, provided the original author and source are credited.

\begin{abstract}
Urinary bladder catheterization and drainage are the commonly done procedures in hospitalized patients. We are reporting a rare occurrence of spontaneous knotting of a Foley catheter in a 10 year's old agitated boy after $12 \mathrm{~h}$ of successful catheterization and adequate drainage. Trans-abdominal ultrasound-guided suprapubic puncture of the none deflating Foley catheter balloon followed by gentle and sustained traction was used to remove the spontaneously knotted Foley catheter inside the urinary bladder. We recommend health care providers should consider spontaneous knotting of Foley catheter as cause of none draining Foley catheter. Securing the catheter and control of agitation can prevent this complication.
\end{abstract}

Keywords: Catheter knotting; Spontaneous; Agitation

\section{Background}

Foley catheter insertion is one of the commonly performed procedures in hospitalized patients. It is estimated that $10 \%$ to $15 \%$ of hospitalized patients will be catheterized [1]. The causes for failure of the drainage of the Foley catheter include port blockade, manufacturing failure and crystal formation. Knotting of the catheter was reported to be rare with estimated occurrence of 0.2 per 100.000 catheterizations [2]. The suggested mechanism is excessively inserting of the catheter with subsequent coiling, When the bladder decompresses, the catheter tip migrate through a coil there by creating a knot [3]. But the possibility of migration of the catheter with subsequent knotting in agitated patient was not mentioned. We are reporting this case to increase awareness of health care providers to the rare cause of not draining Foley catheter and its management.

\section{Case Report}

A 10 year old boy from rural Ethiopia was admitted to the Addis Ababa burn emergency and trauma (AaBET) hospital with a diagnosis of moderate head injury secondary to a fall from a height of $10 \mathrm{~m}$ while climbing a tree. He was aphasic with some agitation and was on supportive management. On further evaluation, the patient had sustained a brain contusion without any other site significant trauma.

As part of his supportive management, he was catheterized with a 12 Fr Foley catheter on the day of admission. His urine output was adequate for the first $12 \mathrm{~h}$ of catheterization. The next day morning the catheter suddenly failed to drain for the subsequent $4 \mathrm{~h}$. The patients started to have an exacerbation of his baseline agitation and were found to be excessively straining. On further evaluation, he was found to have a full bladder but the catheter was not draining. A trial of irrigation of the Foley catheter, followed by a trial of deflation of the catheter balloon was failed. A subsequent attempt to rupture the balloon via hyperinflation also failed.
Trans-abdominal ultrasound-guided suprapubic puncture of the non-deflating Foley catheter balloon was performed. Then, with gentle and sustained traction, the catheter was removed. Upon removal of the catheter, the cause of catheter blockade was found to be spontaneous knotting of the urinary catheter proximal to the balloon while inside the urinary bladder (Figure 1). After the removal, the balloon was examined for any missing fragments. Post extraction of the Foley catheter, the patient was able to void without difficulty and suffered no other complications.

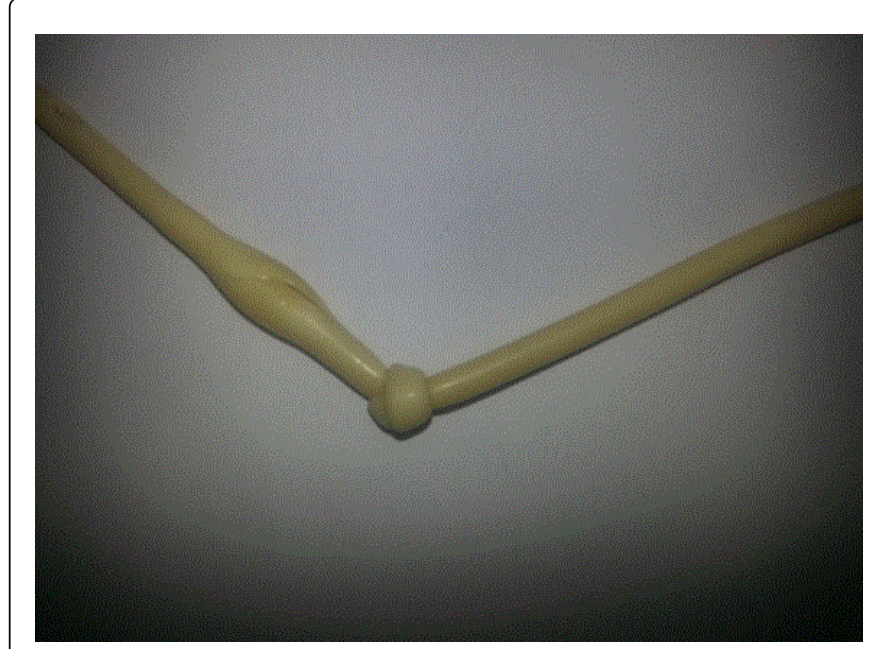

Figure 1: Spontaneously knotted Foley catheter with punctured balloon, Retrieved from 10 year old Ethiopian boy, 2017.

\section{Discussion}

We are reporting a rare occurrence of spontaneous knotting of Foley catheter inside the urinary bladder. In this case, a successfully catheterized child developed acute urinary retention after $12 \mathrm{~h}$ of 
catheterization with adequate urine production. The cause of the urinary retention was found to be catheter obstruction due to knotting of the catheter after insertion. Suprapubic puncture of the nondeflating catheter balloon followed by gentle and sustained traction of the catheter was safe and successful.

Failure of Foley catheter drainage in catheterized patients include port blockage secondary to clotted blood, crystals and stone formation. One part of the management is balloon deflation and removal followed by catheter change. In our case, the balloon was unable to be deflated. Causes of failure to deflate can be an obstruction anywhere along the inflation channel or malfunction of the valve. Debris and salts can also precipitate and block the channel [4].

Intravesical knotting is more common in males, neonates, and children [5]. Catheter knotting can occur at any time after catheterization. Various risk factors have been reported including smaller diameter and flexibility of the catheter as well as redundancy of the catheter due to excessive depth of insertion [1]. But patient agitation was not mentioned as a risk factor in previous reports.

Previous reports have theorized, the likely mechanism of spontaneous knotting is a redundant catheter in the bladder lumen coiling around itself and the catheter end looping through these coils. Subsequently the catheter coils tighten into a knot when the catheter is pulled $[5,6]$. Our patient had agitation due to his head injury. We believe the coiling of the catheter occurred when the catheter migrated deeper into the bladder as the patient moved excessively due to his agitation. Subsequently, when the Foley was retracted back to its normal position, it allowed the coiled catheter to become knotted.

Passive aspiration with a syringe, cutting of the catheter, passing a wire through the balloon, and instilling chemicals like ether into the balloon have all been mentioned to be helpful for rupturing a nondeflating Foley catheter [1]. But these methods may not work for a knotted catheter. Similar to our case report, lee and his colleagues from Hong Kong have reported a successful supra pubic rupture of a nondeflating Foley using ultra sound guidance [7].

After the rupture of the balloon, there can be difficulty in removing the Catheter while it is knotted or it can cause urethral damage during removal [8]. Methods have been proposed such as un-knotting using fluoroscopic or endoscopic guidance or Supra pubic cystotomy retrieval $[6,8]$. But these methods are invasive and are more difficult to perform in resource limited settings. Un-knotting can be mandatory if the patient has a narrow urethra as found in neonates or patients with urethral strictures. Sustained traction under local and systemic analgesia, like in the case we are reporting, is one method of retrieval and it is more successful in older children and adults. This complication would have been prevented. If the agitation were controlled and the catheter were secured to childes leg [9].

\section{Conclusion and Recommendation}

Health professionals should consider spontaneous Knotting of a Foley catheter as the cause of not draining Foley catheter. Supra pubic ultrasound guided balloon puncture with gentle and sustained traction is a safe and easy method for management of these patients. Securing the catheter and management of excessive movement caused by agitation can prevent this complication.

\section{Ethics Approval and Consent to Participate}

We have got written consent from the patient's father both for the treatment of the patient and for publication of this case review.

\section{Competing Interests}

The author declares no conflict of interest.

\section{References}

1. Shapiro AJ, Soderdahl DW, Stack RS, North JH (2000) Managing the nondeflating urethral catheter. J Am Board Fam Pract 13: 116-119.

2. Arena B, MaGillivray D, Dougherty G (2002) Urethra catheter knotting: Be aware and minimize the risk. Can J Emerg Med 4:108e10.

3. Mayer E, Ankem MK, Hartano VH, Barone JG (2002) Management of urethral cathete knot in a neonate. Can J Urol 9: 1649e50.

4. Hollingsworth M, Guralnick ML (2004) The management of retained Foley catheters. Can J Urol 11: 2163-2166.

5. Sarin YK (2011) Spontaneous intravesical knotting of urethral catheter. APSP J Case Rep 21: 1-3.

6. Tang PMY, Chung KLY, Leung YCL, Hung JWS, Liu CCW, et al. (2015) Intra-vesical knot of bladder catheter in an extremely low birthweight neonate: A case report. J Pediatr Surg Case Rep 3: 295-297.

7. Kam CW, Tsui KL (2005) Trans-abdominal ultrasound-guided suprapubic puncture of a non-deflating Foley catheter balloon. Hong Kong J Emerg Med 12: 42-45.

8. Gonzálvez Piñera J, Fernández Córdoba M, Vidal Company A (2000) Intravesical knot of Foley catheter: Unusual complication of cystourethrography in children. An Esp Pediatría 53: 601-603.

9. Ozkan A, Okur M, Kaya M, Büyükkaya R, Katranci AO, et al. (2013) An easy technique for removal of knotted catheter in the bladder: Percutaneous suprapubic cystoscopic intervention. Int J Clin Exp Med 6: 603-605. 